\title{
The Heat of Combustion of Beryllium in Fluorine*
}

\author{
K. L. Churney and G. T. Armstrong \\ Institute for Materials Research, National Bureau of Standards, Washington, D.C. 20234
}

(February 11, 1969)

\begin{abstract}
An experimental determination of the energies of combustion in fluorine of polytetrafluoroethylene film and powder and of mixtures of beryllium with polytetrafluoroethylene gives for reaction (1) $\Delta H_{25^{\circ} \mathrm{C}}^{\circ}=$ $-1022.22 \mathrm{~kJ} \mathrm{~mol}^{-1}\left(-244.32 \mathrm{kcal} \mathrm{mol}^{-1}\right)$ with an overall precision of $0.96 \mathrm{~kJ} \mathrm{~mol}^{-1}\left(0.23 \mathrm{kcal} \mathrm{mol}^{-1}\right)$ at the 95 percent confidence limits. The total uncertainty is estimated not to exceed $\pm 3.2 \mathrm{~kJ} \mathrm{~mol}^{-1}$ $\left( \pm 0.8 \mathrm{kcal} \mathrm{mol}^{-1}\right)$. The measurements on polytetrafluoroethylene give for reaction (2a) and reaction (2b) $\Delta H_{25^{\circ} \mathrm{C}}^{\circ}=-10369.7$ and $-10392.4 \mathrm{Jg}^{-1}$, respectively. Overall precisions expressed at the 95 percent confidence limits are 3.3 and $6.0 \mathrm{Jg}^{-1}$, respectively.
\end{abstract}

$$
\begin{aligned}
& \mathrm{Be}(\mathrm{c})+\mathrm{F}_{2}(\mathrm{~g})=\mathrm{BeF}_{2}(\text { amorphous }) \\
& \mathrm{C}_{2} \mathrm{~F}_{4}(\text { polymer powder })+2 \mathrm{~F}_{2}(\mathrm{~g})=2 \mathrm{CF}_{4}(\mathrm{~g}) \\
& \mathrm{C}_{2} \mathrm{~F}_{4}(\text { polymer film })+2 \mathrm{~F}_{2}(\mathrm{~g})=2 \mathrm{CF}_{4}(\mathrm{~g})
\end{aligned}
$$

$\mathrm{Be}_{2} \mathrm{C}$ and $\mathrm{Be}$ metal were observed in a small carbonaceous residue from the combustion of the beryllium-polytetrafluoroethylene mixtures. Methods of analysis for these substances were developed. Gases resulting from the solution of the solid residues in aqueous $\mathrm{KOH}$ were analyzed for $\mathrm{H}_{2}$ and $\mathrm{CH}_{4}$ by differential absorption in molecular sieves at low temperatures.

Key words: Analysis of methane-hydrogen mixtures; beryllium fluoride; beryllium metal; combustion calorimetry; fluorine; heat of formation; molecular-sieve gas analysis; polytetrafluoroethylene.

\section{Introduction}

No direct determination of the heat of formation of crystalline beryllium fluoride by combustion of beryllium in fluorine has been published, probably because of the difficulty of obtaining reasonably complete combustion and the difficulty of obtaining a crystalline beryllium fluoride product.

All the published determinations are indirect and involve the heats of formation of $\mathrm{BeO}(\mathrm{s})$ and $\mathrm{HF}(\mathrm{aq})$. A heat of formation of $\mathrm{BeF}_{2}(\mathrm{~s})$ near -242 kcal mol-1 (see [1] ${ }^{1}$ ) is obtained if one assumes $\Delta H_{f}^{\circ}$ $[\mathrm{BeO}(\mathrm{s})]$ is $-143.1 \mathrm{kcal} \mathrm{mol}^{-1}$ based on Cosgrove and Snyder's [2] study of the direct oxidation reaction. An examination by Parker [3] of other values [4, 5, $6,7]$ for the heat of formation of $\mathrm{BeO}(\mathrm{s})$ suggests the above value may be too positive by approximately one or more kcal mol-1. The uncertainty in the heat of formation of $\mathrm{HF}(\mathrm{aq})$, a few tenths of a kilocalorie per mole, introduces a smaller though still significant effect.

Direct combination of beryllium with fluorine was undertaken to obtain a value for the heat of forma-

\footnotetext{
*This work was supported by the Air Force Office of Scientific Research under Order No. OAR ISSA 65-8 and the Advanced Research Projects Agency under Order No. 20-60.

'Figures in brackets indicate the literature references at the end of this paper.
}

tion of $\mathrm{BeF}_{2}(\mathrm{~s})$ that is independent of the heats of formation of $\mathrm{BeO}(\mathrm{s})$ and $\mathrm{HF}(\mathrm{aq})$. Better than 99 percent conversion of beryllium to beryllium fluoride was obtained by the device of burning a mixture of beryllium and polytetrafluoroethylene (PTFE) in fluorine.

X-ray analysis of the solid combustion products showed that amorphous rather than crystalline $\mathrm{BeF}_{2}$ had been formed. The products also contained unburned beryllium, appreciable quantities of $\mathrm{Be}_{2} \mathrm{C}$, and a residue containing carbon and fluorine. The magnitudes and the uncertainties of the energy corrections for the various constituents of the combustion products are relatively larger fractions of the energy liberated by formation of $\mathrm{BeF}_{2}$ than would be indicated by the degree of completeness of combustion since 65 to 70 percent of the total energy was due to the combustion of PTFE.

Failure to correct for the formation of $\mathrm{Be}_{2} \mathrm{C}$ and the carbonaceous residue would have led to errors of the order of 0.1 percent and 1 percent, respectively, in the heat of formation of $\mathrm{BeF}_{2}$. Consequently, an accurate method for determining the amounts of $\mathrm{Be}_{2} \mathrm{C}$ and the residue as well as unburned beryllium metal was required, and its development constituted an important part of the experimental work. 


\section{Preliminary Combustion Experiments}

Attempts by other workers to burn beryllium foil [8], powder [9], or rod [9] to completion in fluorine have been notably unsuccessful (in general, less than $50 \%$ of the sample has burned). Similar difficulties encountered with aluminum were overcome in this laboratory by burning a pelleted mixture of aluminum and polytetrafluoroethylene powders in 20 atm pressure of fluorine [10]. The applicability of this method to combustion of beryllium was tested using metal powders with two sizes of particles. The first was a powder of $12 \mu \mathrm{m}$ or finer particle size (passing 200 mesh) and 98.9 percent purity, designated as type $\mathrm{BB}$; and the second was a powder of $25 \mu \mathrm{m}$ or finer particle size (passing 100 mesh) and 99.7 percent purity, designated as type NM.

Type NM metal powder in mixtures with ratios of the weight of polytetrafluroethylene to weight of beryllium ranging from 2 to 20 burned with approximately the same percentage combustion, 75 to 90 percent. Spattering of beryllium metal onto the combustion-bomb walls, formation of glassy (lump) $\mathrm{BeF}_{2}$, and corrosion of the holder were minimal when $0.1 \mathrm{~g}$ of metal was mixed with $1.7 \mathrm{~g}$ of polymer. Combustions of type BB beryllium powder in pellets of the last mentioned composition were 99 to 100 percent complete.

Of several sample supports tested only nickel resisted corrosion. Stainless steel and Monel reacted with the beryllium in the pellet to varying degrees. Calcium fluoride disks tended to crack or melt.

Both type BB and NM beryllium powders were burned in the preliminary combustion experiments and some calorimetric measurements were made with each. Only measurements made with the finer powder, type $\mathrm{BB}$, were used in the final experiments because the disadvantage of a lower sample purity in the case of the finer powder was largely offset by its higher completeness of conversion to $\mathrm{BeF}_{2}$. On the basis of experience obtained in the preliminary combustions, some changes in procedure and apparatus were made and are mentioned in the following sections.

A method of determining unburned beryllium accurate to $30 \mu \mathrm{g}$ or better was required. An analysis based upon the reaction of beryllium metal with concentrated $\mathrm{KOH}$ to give hydrogen fulfilled this requirement and is summarized in section 9 .

\section{Materials}

Beryllium. The amounts and assumed states of the impurities of the two beryllium samples are given in table 1. The amounts of the major impurities given in the batch analyses supplied with the samples were checked and, in general, confirmed by a nuclear activation technique. Carbon was determined as $\mathrm{CO}_{2}$ by the Analysis and Purification Section of the National Bureau of Standards. The uncertainties in the amounts of the impurities were found from check analyses where performed; the, remainder are our estimates of the uncertaintıes in the suppliers' analyses. An effort to obtain a check on the assay of metal from measurements of the amount of hydrogen evolved on dissolving the powders in aqueous $\mathrm{HF}$, done in conjuction with other work performed in this laboratory [11], was only suggestive of the general accuracy of the impurity analysis in table 1 , because the quantitative technique for collection of hydrogen had not been fully worked out.

Polytetrafluoroethylene (PTFE). The powder was obtained as a commercial preparation designated as TFE Fluorocarbon Resin, "Teflon 7". It was composed of irregularly shaped particles with an average size of $35 \mu \mathrm{m}$. Polytetrafluoroethylene film, designated as FEP Fluorocarbon Resin film, of $0.0025 \mathrm{~cm}$ thickness, was used to enclose the beryllium-PTFE mixtures. Neither the film nor the powder was modified or specially treated before use.

Fluorine. Two commercial preparations of fluorine were used, one of which was purified specially for the bomb calorimetry work. Samples were periodically analyzed by absorbing the fluorine in mercury and observing the residual pressure of the unreacted gases [16]. The residual gas was analyzed in a mass spectrometer. Typical analyses appear in table 2 . The estimated uncertainties in the amounts of individual impurities include the uncertainty in our measurement of the total mole percent as well as the uncertainties in the relative amounts of impurities that were estimated by the mass spectrometrist. In the case of the purified fluorine a variation was observed in oxygen content, which gave rise to differing total impurities. Data obtained during composition analyzis definitely suggests that the major portion of $\mathrm{SiF}_{4}$ and its variability are due to the reaction of fluorine with the glass walls of the gas analysis bulbs. It may be that the oxygen arose in this or a related process.

\section{Calorimetric Apparatus}

Heat measurements were made with an isothermaljacket, stirred-water calorimeter of the Dickinson design [17] as modified by Prosen and co-workers [18]. One small change was made. The jacket and calorimeter vessel stirrers were coupled by rubber O-rings and pulleys to individual motors mounted on an insulated bracket on the jacket wall to minimize heat transfer between the motors and calorimeter. The jacket-water temperature was held constant to $\pm 0.002{ }^{\circ} \mathrm{C}$ near a value of $31^{\circ} \mathrm{C}$. The connections for the electrical leads between the calorimeter vessel and jacket were designed to insure good thermal contact with the calorimeter jacket.

Timing and temperature-measuring equipment and procedures for making the heat measurements are adequately described elsewhere $[19,20]$.

The combustion reactions were carried out in a commercially available combustion bomb with an internal arrangement similar to that described elsewhere [10]. The only major difference in the bomb arrangement is the presence of a filter to prevent the loss of $\mathrm{BeF}_{2}$ 
TABLE 1. Impurities in beryllium samples

\begin{tabular}{l|c|c|c|c|c}
\hline \hline Impurity a $^{\text {Amount }}$ & $\begin{array}{c}\text { Amout } \\
(\text { weight \%) }\end{array}$ & $\begin{array}{c}\text { Estimated } \\
\text { uncertainty }\end{array}$ & $\begin{array}{c}\text { Assumed } \\
\text { products }\end{array}$ & $\begin{array}{c}\text { Assumed } \\
\Delta H_{R^{\circ} 298} \\
\left(\mathrm{kcal} \mathrm{mol}^{-1}\right)\end{array}$ & Reference \\
\hline
\end{tabular}

Sample BB

\begin{tabular}{|c|c|c|c|c|c|}
\hline $\mathrm{Li}$ & 0.0001 & 0.00005 & $\mathrm{LiF}(\mathrm{c})$ & -147.1 & [See Sec. 8.2]. \\
\hline B & .00004 & .00002 & $\mathrm{BF}_{3}(\mathrm{~g})$ & -271.75 & [12]. \\
\hline $\mathrm{Be}_{2} \mathrm{C}$ & b. .20 & .025 & $(\mathrm{e})$ & $(\mathrm{f})$ & \\
\hline $\mathrm{Be}_{3} \mathrm{~N}_{2}$ & .0393 & .0197 & $\mathrm{BeF}_{2}(\mathrm{~s}), \mathrm{N}_{2}(\mathrm{~g})$ & $(\mathrm{f})$ & \\
\hline $\mathrm{BeO}$ & c. 7252 & .0445 & $\mathrm{BeF}_{2}(\mathrm{~s}), \mathrm{O}_{2}(\mathrm{~g})$ & (f) & \\
\hline $\mathrm{Mg}$ & .01 & .01 & $\mathrm{MgF}_{2}(\mathrm{c})$ & -268.7 & [13]. \\
\hline $\mathrm{Al}$ & c. .0436 & .0004 & $\mathrm{AlF}_{3}(\mathrm{c})$ & -359.5 & {$[12]$.} \\
\hline $\mathrm{Si}$ & ${ }^{\mathrm{c}} .00831$ & .00126 & $\mathrm{SiF}_{4}(\mathrm{~g})$ & -385.98 & [12]. \\
\hline $\mathrm{Ca}$ & .005 & .005 & $\mathrm{CaF}_{2}(\mathrm{c})$ & -290.3 & [14]. \\
\hline $\mathrm{Mn}$ & c. .0056 & .0004 & $\mathrm{MnF}_{3}(\mathrm{c})$ & -238 & [14]. \\
\hline $\mathrm{Fe}$ & c.0795 & .0108 & $\mathrm{FeF}_{3}(\mathrm{c})$ & -235 & {$[14]$. } \\
\hline $\mathrm{Cu}$ & .005 & .0025 & $\mathrm{CuF}_{2}(\mathrm{c})$ & -126.9 & [14]. \\
\hline $\mathrm{Ag}$ & .0005 & .00025 & $\operatorname{AgF}(c)$ & -48.5 & [14]. \\
\hline $\mathrm{Cd}$ & .00007 & .00004 & $\mathrm{CdF}_{2}(\mathrm{c})$ & -167.4 & [12]. \\
\hline $\mathrm{Ni}$ & .009 & .004 & $\mathrm{NiF}_{2}(\mathrm{c})$ & -159.5 & [14]. \\
\hline $\mathrm{Pb}$ & .0005 & .0005 & $\mathrm{PbF}_{2}(\mathrm{c})$ & -158.7 & {$[12]$.} \\
\hline Mo & .001 & .0005 & $\mathrm{MoF}_{6}(\mathrm{~g})$ & -372.35 & [15]. \\
\hline Co & .0004 & .0002 & $\mathrm{CoF}_{3}(\mathrm{c})$ & -187 & {$[14]$. } \\
\hline \multirow[t]{2}{*}{$\mathrm{Cr}$} & .009 & .004 & $\mathrm{CrF}_{5}(\mathrm{c})$ & -350 & {$[14]$.} \\
\hline & 1.14212 & & & & \\
\hline Be (metal) & 98.85788 & $\mathrm{~g} \pm 0.057$ & & & \\
\hline Be (atomic) & 99.26838 & $\mathrm{~g} \pm 0.040$ & & & \\
\hline
\end{tabular}

Sample NM

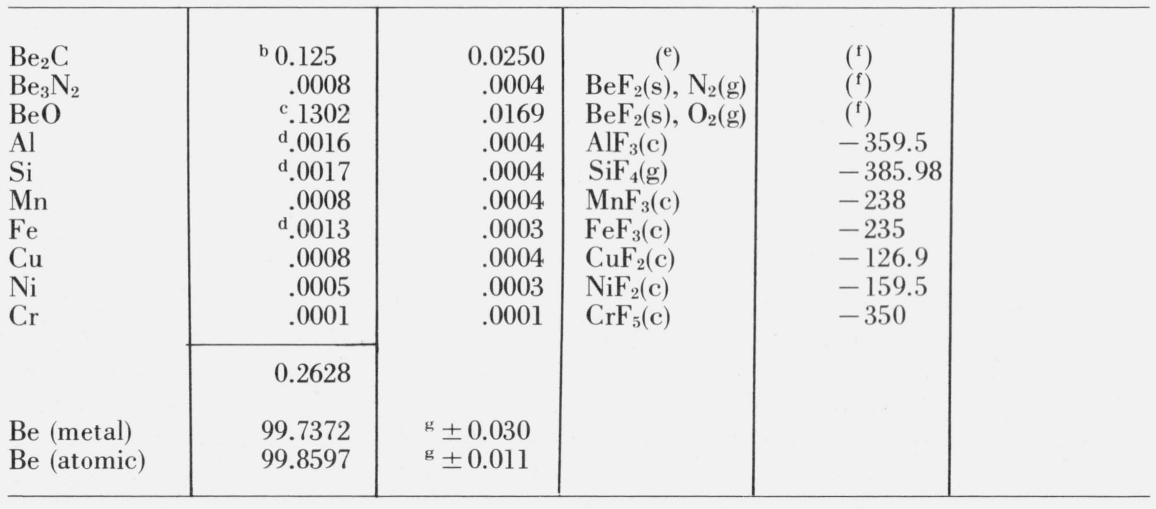

a $\mathrm{C}, \mathrm{N}, \mathrm{O}$ are assumed to be combined as $\mathrm{Be}_{2} \mathrm{C}, \mathrm{Be}_{3} \mathrm{~N}_{2}, \mathrm{BeO}$.

${ }^{b}$ Determined by converting carbon to $\mathrm{CO}_{2}$.

c Determined by nuclear activation.

d Determined by supplier for this sample.

e $\mathrm{Be}_{2} \mathrm{C}$ is formed.

f $\Delta H_{f 298}^{\circ}: \mathrm{Be}_{2} \mathrm{C}(\mathrm{s}),-26 ; \mathrm{Be}_{3} \mathrm{~N}_{2}(\mathrm{~s}),-140.6 ; \mathrm{BeO}(\mathrm{s}),-145 \mathrm{kcal} \mathrm{mol}^{-1}[3]$

$\mathrm{g}$ Square root of the sum of the squares of the individual uncertainties. 
TABLE 2. Typical analyses of Fluorine

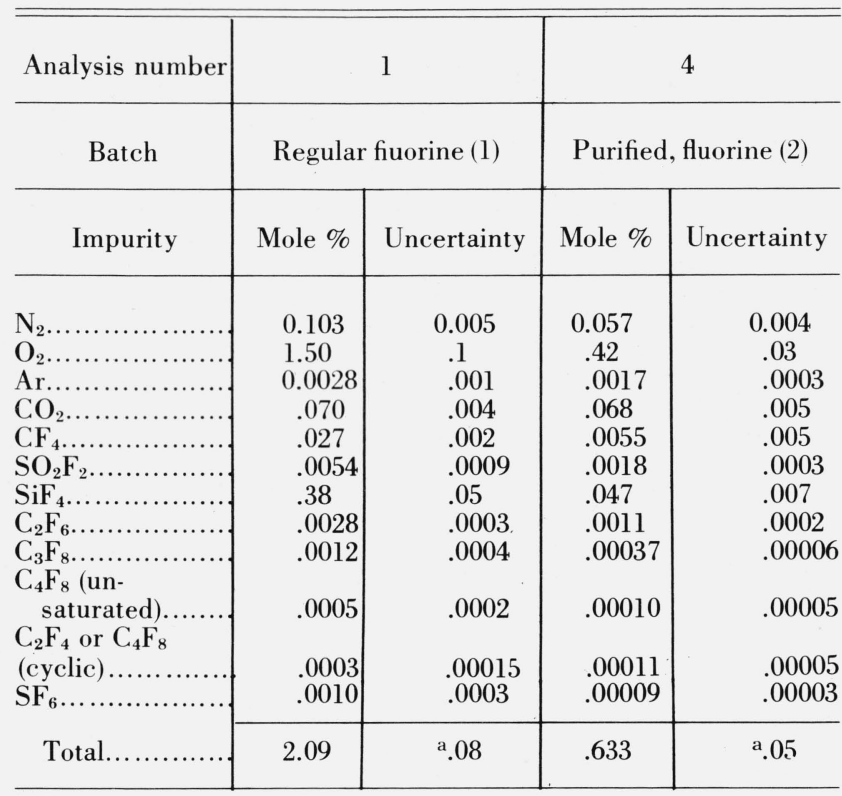

a Total uncertainty is based only on the a priori estimate of the uncertainty of the measure ment of total moles of impurity.

when fluorine is removed from the bomb. The filter element, a Monel fritted disk, is held by lead O-rings in a stainless steel holder that screws into the inside of one port of the bomb head. Beryllium-PTFE pellets were burned in a shallow nickel cup resting on a nickel base plate that fitted into the bottom of the stainless steel liner of the combustion bomb. Combustions of PTFE powder and film alone were carried out on a Monel holder similar to that described by Domalski and Armstrong [10] after removal of the base plate, the cup, and the filter from the bomb.

The standard initial calorimeter for the fluorine experiments consisted of the combustion bomb with the internal arrangment for a beryllium-PTFE combustion, $6 \mathrm{~cm}$ of $0.005-\mathrm{cm}$ diam tungsten fuse wire connected between two aluminum electrodes, an electrical heater (see [10] for a description of the heating element), a platinum resistance thermometer, and the calorimeter vessel with a weighed quantity of water.

\section{Fluorine Manifold}

The manifold and accessory equipment for filling the combustion bomb with fluorine, emptying it, and obtaining samples of fluorine and volatile products of combustion are nearly identical to that described by Domalski and Armstrong [10]. Two differences are noteworthy:

1. In the preliminary fluorine combustions, the bomb was connected to the manifold by a line
(1/4 in O.D., 0.035 in wall-thickness Monel tubing) containing a filter of fritted monel. Prior to the loading with fluorine the bomb was evacuated by a vacuum pump, via the manifold and this line containing the filter, until the pressure in the manifold was less than $10^{-2} \mathrm{~mm} \mathrm{Hg}$. Occasionally premature ignition occurred (two berylliumPTFE pellets and one PTFE pellet burned prematurely). The subsequent discovery of severe corrosion of the monel fritted filter suggested the premature ignition was due to poor evacuation of the bomb. Accordingly, in the final combustion experiments, the filter was removed from the line and, in addition, a second vacuum system was connected to the other bomb port via a short $3 / 8$ in O.D. copper line. A thermocouple gage was mounted on this line at its connection to the bomb to give a more accurate indication of the pressure inside the bomb. The bomb was evacuated by both vacuum pumps until the manifold pressure was less than $10^{-2} \mathrm{~mm} \mathrm{Hg}$ and the bomb pressure was less than $10^{-3} \mathrm{~mm} \mathrm{Hg}$. No further trouble was encountered with premature ignition in the final series of fifteen combustion experiments.

2. A ballast tank was installed in the manifold to allow the reduction of the pressure of the entire gaseous contents of the bomb after combustion to $1 \mathrm{~atm}$ prior to sampling for mass spectrometer analysis.

\section{Beryllium Manipulation}

On the basis of consultation of the literature [21, $22,23,24]$ and the experience of others who handled beryllium $[25,8]$, special procedures and certain equipment arrangements were deemed necessary for the safe handling of beryllium.

All manipulations involving the transfer or fluorinecombustion of beryllium powder were carried out in a high-exhaust-velocity fume hood which was decontaminated regularly by washing with dilute hydrochloric acid and water. The fluorine manifold and the calorimeter were in the hood and were protected from contamination by enclosure of the former in a watertight lucite box and the latter in a polyethylene bag with a removable top. The manifold valves were operated by extension rods passing through PTFE O-ring seals in the box. The calorimeter controls were mounted outside the hood. The Monel fritted-disk filter mounted on the lower side of the combustion bomb head under the fluorine port was to prevent the escape of $\mathrm{BeF}_{2}$ into the manifold while fluorine and volatile combustion products were being removed.

All transfers of solid combustion products were carried out in a dry box, after which all working surfaces of the box, the combustion bomb, and contaminated equipment were washed with water. The atmosphere of the box and box entry chamber was filtered and dried prior to removal of any equipment. 


\section{Combustion Experiments}

\subsection{Calibration}

The calorimeter was calibrated by burning benzoic acid (standard sample $39 \mathrm{~h}$ ) in high purity $(99.996 \%)$ oxygen at $30 \mathrm{~atm}$ pressure. The internal bomb arrangement differed from that in the standard fluorine bomb, as given in section 4, as follows: (1) the absence of the filter, nickel pellet cup, and aluminum electrodes; (2) the use of a Monel, instead of a nickel, base plate; and (3) the presence of platinum electrodes, a platinum crucible, a $2-\mathrm{cm}$ piece of chromel-C fuse wire $(0.16-\mathrm{mm}$ dia) supported over the sample by platinum wire, and $1 \mathrm{~cm}^{3}$ of distilled water. The energy equivalent of the oxygen calorimeter, calculated using standard procedures $[19,20]$, was $14,621.0 \mathrm{~J}^{\circ} \mathrm{C}^{-1}$ with a standard deviation of the mean for seven experiments of 1.1 $\mathrm{J}^{\circ} \mathrm{C}^{-1}$. The energy equivalent of the standard fluorine calorimeter was $14,656.68 \mathrm{~J}^{\circ} \mathrm{C}^{-1}$.

\subsection{Pellet Preparation}

The weights of pellets of PTFE formed by rapid compression of powder decreased appreciably with time (as much as $400 \mu \mathrm{g}$ in $20 \mathrm{hr}$ ). Consequently, PTFE pellets were weighed after being stored in the balance case for 1 month, and pellets of both powder and film were formed by slow compression in the die pieces.

Beryllium-PTFE mixtures were prepared in PTFE bags to reduce losses during transferring and pelleting that occurred in earlier mixing techniques [10] where no bags were used. Since being developed for the present study, this pelleting technique has been further modified and applied successfully to the combustion of other substances in fluorine [26-29]. A bag was made out of PTFE film. The film was sealed by sandwiching a fold in the film layers between two strips of aluminum and gently heating the exposed crease near an open flame. For preparation of the pellets about $1.7 \mathrm{~g}$ of PTFE and $0.1 \mathrm{~g}$ of beryllium were trans- ferred to the weighed bag. The materials were weighed after each addition. The bag contents were mixed by moving the enclosed bubble of air through the mixture. The bag was then punctured, placed in a pellet die piece, slowly -compressed into a pellet, and stored in a desiccator.

Weight changes for a number of pellets prepared during this research are summarized in table 3 . The method of pellet preparation in the final combustion experiments was different from that used in the preliminary experiments in the following ways:

1. Beryllium powder was added to the bag before the PTFE powder in final experiments. This reduces the possibility that any weight loss on sealing the bag (item (1), table 3 ) is due to loss of beryllium rather than PTFE. However, in all cases this weight loss was assumed to be loss of PTFE bag.

2. A larger puncture was made in the bag and pressure was applied more slowly to the die pieces in forming a pellet in final experiments $(30 \mathrm{~min}$ rather than $2 \mathrm{~min}$ ). This resulted in better agreement between the weight of the pellet just before it was burned and the weight of the sealed bag plus contents just prior to pelleting (item (3), table 3). The weights of all newly formed pellets except sample 6 of the preliminary combustions were greater than the weights before pelleting (item (2), table 3); however, the weights of the pellets approached a constant weight in the final experiments in a shorter period of time than in the preliminary experiments.

3. More closely fitting die pieces were used in the preparation of the pellets of final experiments. As a consequence, no PTFE was found on the die pieces and no correction was necessary for loss of PTFE.

\subsection{Experimental Heat Measurements}

Eight experiments summarized in table 4 were used to establish the energy of combustion of the PTFE

TABLE 3. Weight changes $(\mu g)$ in beryllium-PTFE pellet preparation

\begin{tabular}{|c|c|c|c|c|c|c|c|c|c|c|c|}
\hline Series & & & minar & combus & & & & & combu & & \\
\hline Sample No.* & $1(1)$ & 2 & 3 & 4 & $5(3)$ & 6 & 1 & $2(4)$ & $3(5)$ & $4(6)$ & $5(7)$ \\
\hline $\begin{array}{l}\text { (1) Wt. after minus } \\
\text { wt. before sealing }\end{array}$ & -72 & -18 & -29 & -246 & -278 & -88 & -36 & -39 & -115 & -15 & -24 \\
\hline $\begin{array}{l}\text { (2) Wt. after minus } \\
\text { wt. before pelleting }\end{array}$ & 201 & 198 & 125 & 282 & 23 & 259 & 151 & 207 & 218 & 168 & 215 \\
\hline $\begin{array}{l}\text { (3) Wt. prior to combustion minus wt. } \\
\text { before pelleting }\end{array}$ & 51 & 46 & -15 & -23 & -45 & -19 & -26 & -14 & 22 & 2 & -1 \\
\hline $\begin{array}{l}\text { Elapsed time (days) between weigh- } \\
\text { ing before pelleting and before } \\
\text { combustion }\end{array}$ & 12 & 18 & 54 & 56 & 60 & 61 & 15 & 16 & 17 & 18 & 3 \\
\hline
\end{tabular}


powder. The combustion in each case was almost entirely complete. The residues recovered in no case amounted to more than 0.02 percent of the original mass. The energy of combustion of the PTFE film was determined separately in a series of three combustion experiments summarized in table 5 . The degree of completeness of these combustions was comparable to that of the powder.

Four final combustions of beryllium-PTFE pellets were successfully completed and are listed in table 6 . Three preliminary combustion experiments of beryllium-PTFE pellets are also listed in table 6 for sake of comparison and discussion in section 8.4.

\subsection{Analysis of Combustion Products}

After a PTFE combustion, the area of the sample holder that had been in contact with the pellet was covered with a thin black film. This minute residue was weighed by difference by wiping off the film and was assumed to be unburned PTFE. Correction for the effect of adsorption of water by the fluoride coated holder was made by determining the increase in mass of the holder as a function of time and extrapolation to the time the holder was first exposed to air. The corrected mass of residue is the second entry in table 4 and 5 .

Samples of the volatile combustion products were analyzed with a mass spectrometer after absorption of the fluorine in mercury. Results of some typical analyses are presented in table 7 in terms of the differences in the amounts of impurity present after a combustion from those present prior to a combustion. The uncertainties include those of the fluorine analyses as well as the volatile combustion product analyses. The average changes in higher fluorocarbons listed at the bottom of table 7 were used in calculating item 8 of table 4, 5, and 6 . 
TABLE 4. ${ }^{\mathrm{a}}$ Combustion of PTFE powder



a Symbols employed are explained in refs. [31, 32].

${ }^{\mathrm{b}} \Delta E_{1 \mathrm{BP}}=\left[E(\right.$ calor $)+E^{i}($ cont $\left.)\right] \times\left(-\Delta t_{e}\right){ }^{\prime}$

c $\Delta E($ gas $)=\Delta E($ gas $)\left[p_{i}{ }^{(\text {gas })}+\Delta E^{\mathrm{f}}(\text { gas })\right]_{p f(\text { gas })}^{\circ}$ 
TABLE 5. ${ }^{\mathrm{a}}$ Combustion of PTFE film

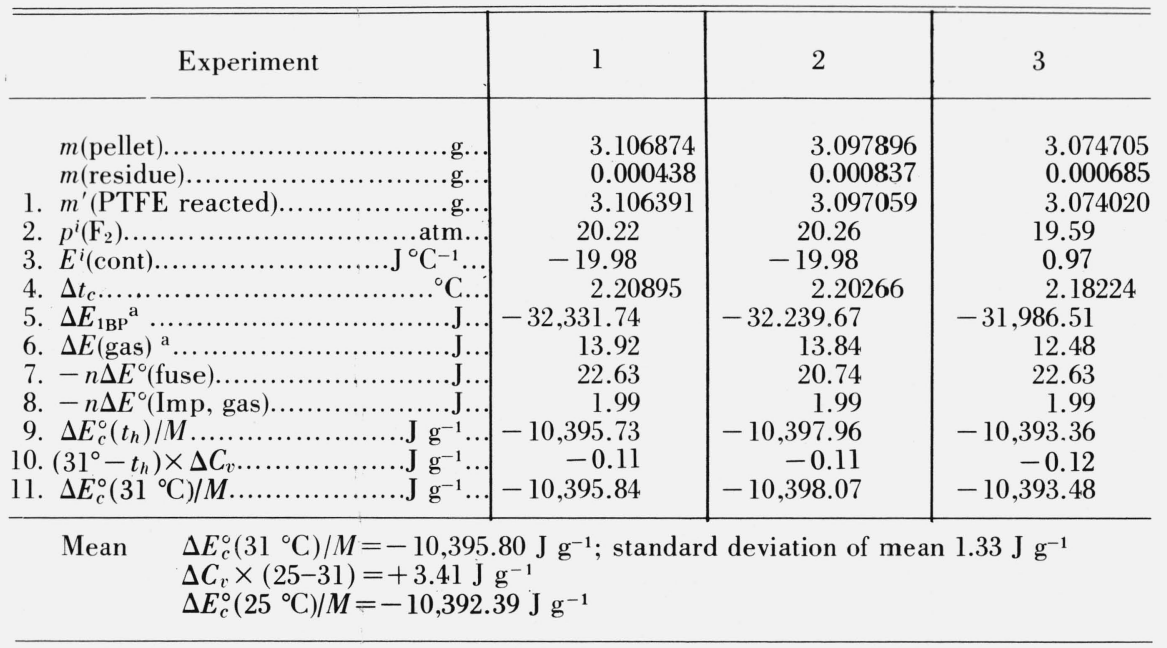

a See footnotes to table 4 . 
TABLE $6 .{ }^{\text {a }}$ Combustion of beryllium-PTFE mixtures

\begin{tabular}{|c|c|c|c|c|c|c|c|}
\hline \multirow[b]{2}{*}{ Number, type of $\mathrm{Be}$} & \multicolumn{3}{|c|}{ Preliminary combustions } & \multicolumn{4}{|c|}{ Final combustions } \\
\hline & $1, \mathrm{NM}$ & $2, \mathrm{BB}$ & $3, \mathrm{NM}$ & $4, \mathrm{BB}$ & $5, \mathrm{BB}$ & $6, \mathrm{BB}$ & $7, \mathrm{BB}$ \\
\hline 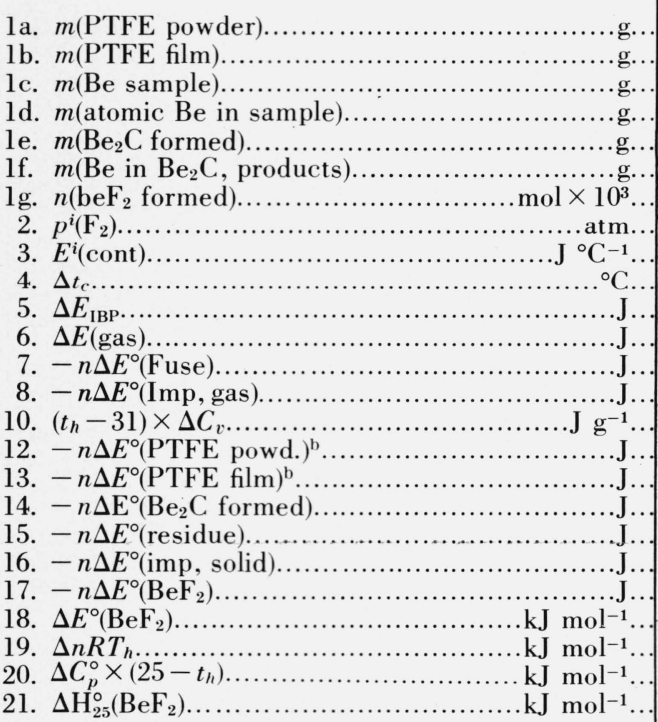 & $\begin{array}{r}2.031374 \\
0.528567 \\
.100614 \\
.100473 \\
.005316 \\
.003266 \\
8.72939 \\
19.99 \\
-85.06 \\
2.42047 \\
-35,270.17 \\
8.30 \\
22.61 \\
9.80 \\
0.44 \\
21,070.69 \\
5,494.64 \\
-143.96 \\
-62.85 \\
-2.96 \\
-8,873.90 \\
-1,016.55 \\
-2.52 \\
+0.18 \\
-1,018.89\end{array}$ & $\begin{array}{r}2.159857 \\
0.494459 \\
.089802 \\
.089145 \\
.000033 \\
.000128 \\
9.86097 \\
20.08 \\
8.92 \\
2.55480 \\
-37,467.67 \\
8.54 \\
22.61 \\
-12.37 \\
0.37 \\
22,403.55 \\
5,140.11 \\
-0.89 \\
-32.70 \\
-10.93 \\
-9,949.75 \\
-1,009.00 \\
-2.52 \\
+0.18 \\
-1,011.34\end{array}$ & $\begin{array}{c}2.187286 \\
0.537886 \\
.104813 \\
.104666 \\
.006447 \\
.003947 \\
9.19720 \\
20.35 \\
-32.09 \\
2.55497 \\
-37,365.39 \\
9.62 \\
21.69 \\
-12.37 \\
0.26 \\
22,688.30 \\
5,591.62 \\
-174.58 \\
-141.64 \\
-3.08 \\
-9,385.83 \\
-1,020.51 \\
-2.52 \\
+0.19 \\
-1,022.84\end{array}$ & $\begin{array}{r}1.983933 \\
0.462695 \\
.089153 \\
.088501 \\
.000101 \\
.000167 \\
9.78562 \\
18.87 \\
9.20 \\
2.40858 \\
-35,323.95 \\
7.10 \\
20.79 \\
-12.37 \\
0.23 \\
20,579.02 \\
4,809.98 \\
-2.74 \\
-47.66 \\
-10.85 \\
-9,980.68 \\
-1,019.93 \\
-2.53 \\
+0.19 \\
-1,022.27\end{array}$ & $\begin{array}{r}2.479838 \\
0.473074 \\
.080249 \\
.079662 \\
.000035 \\
.000117 \\
8.80151 \\
18.73 \\
9.90 \\
2.69866 \\
-39,580.11 \\
9.60 \\
18.86 \\
-12.37 \\
0.14 \\
25,723.19 \\
4,917.92 \\
-0.95 \\
-40.88 \\
-9.77 \\
-8,974.51 \\
-1,019.65 \\
-2.53 \\
+0.20 \\
-1,021.98\end{array}$ & $\begin{array}{c}2.005580 \\
0.436645 \\
.113741 \\
.112909 \\
.000178 \\
.000243 \\
12.49062 \\
18.90 \\
9.56 \\
2.59427 \\
-38,048.19 \\
6.35 \\
20.75 \\
-12.37 \\
0.11 \\
20,803.80 \\
4,539.23 \\
-4.82 \\
-37.75 \\
-13.84 \\
-12,746.84 \\
-1,020.51 \\
-2.53 \\
+0.20 \\
-1,022.84\end{array}$ & $\begin{array}{c}2.082622 \\
0.464008 \\
.091545 \\
.090875 \\
.000102 \\
.000171 \\
10.05448 \\
18.84 \\
9.47 \\
2.49879 \\
-36,647.63 \\
7.50 \\
22.63 \\
-12.37 \\
0.12 \\
21,602.93 \\
4,823.68 \\
-2.76 \\
-32.93 \\
-11.14 \\
-10,250.09 \\
-1,019.46 \\
-2.53 \\
+0.20 \\
-1,021.79\end{array}$ \\
\hline
\end{tabular}

Mean $\Delta \mathrm{H}_{25}^{\circ}\left(\mathrm{BeF}_{2}\right)^{\mathrm{c}}=-1,022.22 \mathrm{~kJ} \mathrm{~mol}^{-1}\left(-244.32 \mathrm{kcal} \mathrm{mol}^{-1}\right)$ : standard deviation of mean $0.23 \mathrm{~kJ} \mathrm{~mol}^{-1}\left(.05 \mathrm{kcal} \mathrm{mol}^{-1}\right)$.

a See footnotes to table 4.

der and PTFE bags were corrected to $t_{h}$ for each experiment. 
TABLE 7. Typical volatile product analysis and increase in constituents on combustion ${ }^{\text {a }}$

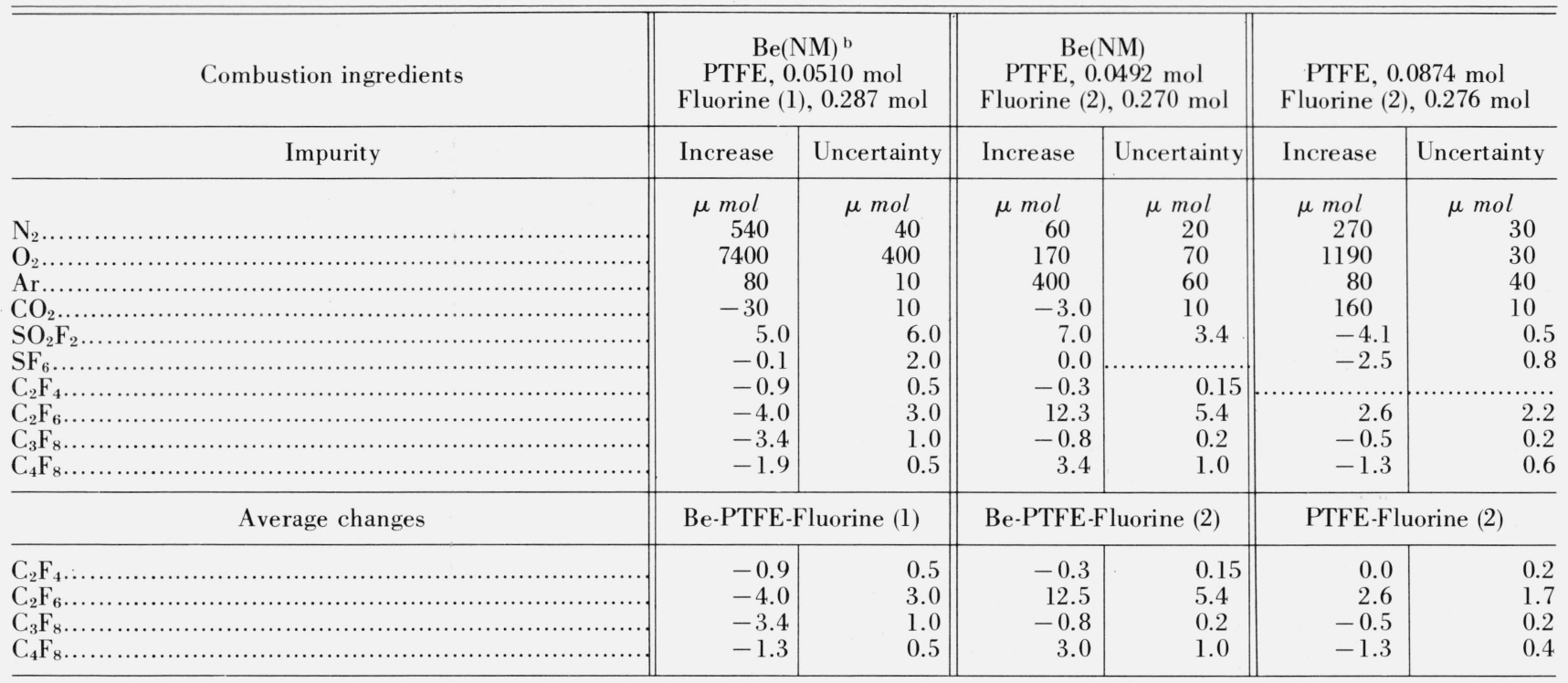

a See table 2 for appropriate typical fluorine analysis.

${ }^{\mathrm{b}} \mathrm{Be}(\mathrm{NM})$ is the type NM beryllium sample.

After combustion of a beryllium-PTFE mixture, the exterior of the bomb was dried in the dry box entry chamber by evacuation of the entry chamber. After disposal of volatile combustion products by use of the manifold, the bomb was filled with 1 atm pressure of helium and was opened in the dry box in which the atmosphere has been dehumidified until the dew point was $-78{ }^{\circ} \mathrm{C}$. The solid combustion products from the bomb were stored in vials or petri dishes in a desiccator.

The inner surfaces of the bomb were covered with a fine white hygroscopic powder after a beryllium-PTFE combustion. The larger part of this powder was confined to the nickel pellet cup, where it covered a small amount of mixture of black particles. Analysis of the beryllium content (measured as $\mathrm{BeO}$ ) of a known weight of the white powder showed it to be correct for $\mathrm{BeF}_{2}$; the $\mathrm{x}$-ray pattern was similar to that observed by $\mathrm{W}$ arren and Hill [30] for vitreous $\mathrm{BeF}_{2}$.
The contents of the pellet cup were analyzed by reaction with hot concentrated $\mathrm{KOH}$, for the amount of unburned beryllium (as $\mathrm{H}_{2}$ gas) and beryllium carbide (as $\mathrm{CH}_{4}$ gas) by the procedure described in section 9 . The black residue remaining in the $\mathrm{KOH}$ solution was filtered, washed, dried, and weighed. Its appearance suggested a mixture of unburned PTFE and fine black powder.

Residues from the beryllium-PTFE combustions were collected quantitatively in glass fritted-disk filters, weighed, and sent to the NBS Analysis and Purification Section for analysis of either carbon or fluorine content.

Table 8 is a summary of the combustion product analyses. Details of the determinations of beryllium and beryllium carbide are given in section 9. Precisions of the determinations of beryllium and beryllium carbide are the 95 percent confidence limits based on the standard deviation of the single measurements of the moles of gas cited in section 9.

TABLE 8. Results of combustion-product analyses

\begin{tabular}{|c|c|c|c|c|c|c|c|c|}
\hline \multirow{2}{*}{$\begin{array}{l}\text { Expt. } \\
\text { No. }\end{array}$} & \multirow{2}{*}{$\begin{array}{l}\text { Unburned } \\
\text { beryllium }\end{array}$} & \multirow{2}{*}{ Precision } & \multirow{2}{*}{$\begin{array}{l}\mathrm{Be}_{2} \mathrm{C} \text { in } \\
\text { products }\end{array}$} & \multirow{2}{*}{ Precision } & \multirow{2}{*}{$\begin{array}{l}\text { Weight of } \\
\text { residue }\end{array}$} & \multirow{2}{*}{ Precision } & \multicolumn{2}{|c|}{ Residue analysis } \\
\hline & & & & & & & $\% \mathrm{C}$ & $\% \mathrm{~F}$ \\
\hline & $m g$ & $m g$ & $m g$ & $m g$ & $m g$ & $m g$ & & \\
\hline \multicolumn{9}{|c|}{ Preliminary combustions } \\
\hline 1. & 18.536 & 0.037 & 5.442 & 0.125 & 1.683 & 0.04 & 54.7 & \\
\hline 2. & 0.148 & .005 & 0.213 & .015 & 1.706 & .04 & 34.0 & \\
\hline 3. & 17.832 & .034 & 6.578 & .059 & 2.131 & .04 & 87.8 & \\
\hline \multicolumn{9}{|c|}{ Final combustions } \\
\hline 4. & 0.144 & 0.003 & 0.279 & 0.003 & 2.420 & 0.04 & & \\
\hline 5. & .184 & .006 & .195 & $\begin{array}{r}.003 \\
.016\end{array}$ & 2.011 & $\begin{array}{r}.04 \\
.04\end{array}$ & 35.3 & \\
\hline 6. & .098 & .003 & .405 & .034 & 1.916 & .04 & & 9.4 \\
\hline 7. & .091 & .003 & .285 & .011 & 1.670 & .04 & & 5.4 \\
\hline
\end{tabular}




\section{Discussion and Results}

\subsection{Treatment of Combustion Data}

The notation of tables 4, 5, and 6 and method of standard state corrections are explained in detail elsewhere [31, 32]. The numbered entries are: (1) the mass (weight in vacuum) of PTFE reacted (tables 4 and 5), or moles of beryllium fluoride (table 6, item lg) formed; (2) the initial pressure of fluorine; (3) corrections to be added to the energy equivalent of the standard fluorine calorimeter for fluorine, combustion sample, and variations in internal bomb arrangement; (4) the observed increase in calorimeter temperature corrected for heat exchanged between the calorimeter and its surroundings and for stirring; (5) the energy equivalent of the actual calorimeter multiplied by the corrected temperature rise; (6) the net correction due to the hypothetical compression and decompression of bomb gases; (7) the correction for fuse energy; (8) the correction for the change in the amounts of higher gaseous fluorocarbons as estimated in table 3 ; (9) the energy of combustion of PTFE powder (table 4) or film (table 5) at the temperature, $t_{h}$, to which the isothermal bomb process is referred in each experiment; (10) the correction to be added to the energy of combustion at $t_{h}$ of PTFE powder or film per unit mass to obtain the value at $31{ }^{\circ} \mathrm{C}$ (tables 4 and 5 ) or vice versa (table 6 ); (11) the standard state energy change at $31{ }^{\circ} \mathrm{C}$ per gram of PTFE film (table 4) or powder (table 5) for reaction (2); (12) and (13) corrections for the energy contributed by the PTFE powder and by the film assuming both are completely converted to $\mathrm{CF}_{4}$; (14) the correction for the formation of $\mathrm{Be}_{2} \mathrm{C}(\mathrm{s})$ according to reaction (4);

$$
2 \mathrm{Be}(\mathrm{s})+\mathrm{CF}_{4}(\mathrm{~g}) \rightarrow \mathrm{Be}_{2} \mathrm{C}(\mathrm{s})+2 \mathrm{~F}_{2}(\mathrm{~g})
$$

(15) the correction for carbon, according to reaction (5a), and unburned PTFE, according to reaction (5b) in the combustion products;

$$
\begin{aligned}
\mathrm{CF}_{4}(\mathrm{~g}) & \rightarrow \mathrm{C}(\mathrm{s})+\mathrm{F}_{2}(\mathrm{~g}) \\
2 \mathrm{CF}_{4}(\mathrm{~g}) & \rightarrow \mathrm{C}_{2} \mathrm{~F}_{4}(\text { polymer film })+2 \mathrm{~F}_{2}(\mathrm{~g})
\end{aligned}
$$

(16) the correction for the combustion of the impurities in the sample of beryllium excluding $\mathrm{Be}_{2} \mathrm{C}$; (17) the energy change associated with the formation of $\mathrm{BeF}_{2}(\mathrm{~s})$, alone, at the temperature $t_{h}$; (18) the same energy change divided by the moles of $\mathrm{BeF}_{2}(\mathrm{~s})$ formed; (19) the correction to obtain the enthalpy change per mole of $\mathrm{BeF}_{2}(\mathrm{~s})$ at $t_{h} ;(20)$ the standard state enthalpy of formation of $\mathrm{BeF}_{2}(\mathrm{~s})$ at $25^{\circ} \mathrm{C}$ by reaction (1).

For item (1) of tables 4 and 5, the PTFE "residue" is treated as unburned PTFE. Items la-le of table 6 list the contents of the beryllium-PTFE pellet. Item $\mathrm{lg}$ of table 6 is computed from item $1 \mathrm{~d}$, table 6 , minus the sum of item lf, table 6 , and the weight of unreacted beryllium in table 8 . Thus, this gives the total number of moles of $\mathrm{BeF}_{2}(\mathrm{~s})$ formed from $\mathrm{BeO}(\mathrm{s})$ and $\mathrm{Be}_{3} \mathrm{~N}_{2}(\mathrm{~s})$ as well as $\mathrm{Be}(\mathrm{s})$. In item (5), the ignition energy was assumed to be zero (as in the calibration experiments). Items (9) and (10) are based on the mass of PTFE film and powder before the pellet was formed. The loss in weight occurring on sealing the bag was assumed to be loss of PTFE film. No correction was applied to the film weight for loss during pelleting unless film was found on the pellet die pieces. Item (14) is based on a value of $\Delta E^{\circ}\left(31^{\circ} \mathrm{C}\right)$ of $27.08 \mathrm{~J} \mathrm{mg}^{-1}$ of $\mathrm{Be}_{2} \mathrm{C}(\mathrm{s})$ formed and item le. Item (15) assumes the residue consists of carbon and unburned PTFE film (pieces of film were observed in combustion residues). Experiments $1,2,3$, and 5 are based on the analyses cited in table 8 while the remainder assume 34.6 percent carbon by weight (the average of experiments 2 and 5). $\Delta E^{\circ}\left(31{ }^{\circ} \mathrm{C}\right)$ for reaction $(6 \mathrm{~b})$ was taken to be $77.19 \mathrm{~J} \mathrm{mg}^{-1}$ of carbon. Item (16) is based on table 1 . The corrections used were $2.22 \mathrm{~J} \mathrm{~g}^{-1}$ for sample NM and $58.35 \mathrm{~J} \mathrm{~g}^{-1}$ for sample BB. The temperature of the hypothetical isothermal process to which each of items (2) through (13) refers, $t_{h}$, is the final temperature the calorimeter would have had for each experiment if no heat had been exchanged with the surroundings and the stirring energy was zero.

\subsection{Auxiliary Data}

Buoyancy corrections for the masses of beryllium, PTFE powder, and PTFE film were calculated using densities of 1.84 [33], 2.15, and $2.21 \mathrm{~g} \mathrm{~cm}^{-3}$, respectively. The densities of the PTFE film and powder were determined experimentally.

A heat of formation of $\mathrm{WF}_{6}(\mathrm{~g})$ of $-416 \mathrm{kcal} \mathrm{mol}^{-1}$ [34] was used to compute the fuse energy (22.61 J for $6 \mathrm{~cm}$ of wire).

Data for the net heat correction for the hypothetical compression and decompression of bomb gases are based on the parameters of the Lennard-Jones 6-12 potential function determined for fluorine by White, $\mathrm{Hu}$, and Johnston [35] and for $\mathrm{CF}_{4}$ by Douslin [36]. Second virial coefficients for the mixture of $F_{2}(g)$ and $\mathrm{CF}_{4}(\mathrm{~g})$ in the reaction products were calculated from those of the pure products. The values used for $C_{v}$ $(20 \mathrm{~atm}, 304.15 \mathrm{~K})$ and $C_{v}^{\circ}(298.15 \mathrm{~K})$ for fluorine and $C_{v}(298.15 \mathrm{~K})$ for $\mathrm{CF}_{4}$ were $5.54,5.499$ [37], and 12.607 [38] cal $\mathrm{deg}^{-1} \mathrm{~mol}^{-1}$, respectively. Values of $C_{p}$ in cal $\mathrm{deg}^{-1} \mathrm{~g}^{-1}$ for beryllium, PTFE, and $\mathrm{BeF}_{2}(\mathrm{c})$ were taken to be 0.436 [39], 0.280 [40], 0.264 [41], respectively.

The heats of formation used in the calculation of heat corrections for impurities in the beryllium samples, the formation of $\mathrm{Be}_{2} \mathrm{C}$, and the berylliumPTFE residues are those given in table 1 and a heat of formation of -221 [12] kcal mol-1 for $\mathrm{CF}_{4}(\mathrm{~g})$. While this value for $\mathrm{CF}_{4}$ has been superseded [27], the change introduced in this correction is insignificant in comparison to other errors (see table 10).

For $\Delta H_{F}^{\circ}[\mathrm{LiF}(\mathrm{c})]$, the heat of solution found by Stephenson, Hopkins, and Wulff [42] was combined with values for the heats of formation of $\mathrm{Li}^{+}(\mathrm{aq})$ [43] and $\mathrm{F}^{-}(\mathrm{aq})$ [12]. The heats of formation of $\mathrm{C}_{2} \mathrm{~F}_{4}(\mathrm{~g})$, $\mathrm{C}_{2} \mathrm{~F}_{6}(\mathrm{~g}), \mathrm{C}_{3} \mathrm{~F}_{6}(\mathrm{~g}), \mathrm{C}_{3} \mathrm{~F}_{8}(\mathrm{~g})$, and $\mathrm{C}_{4} \mathrm{~F}_{8}(\mathrm{~g})$ used to calculate the heat correction for the change in higher fluorocarbon content of the gases in a fluorine combus- 
TABLE 9. Calorimetric results

\begin{tabular}{|c|c|c|c|c|c|}
\hline Quantity & Units & Value & $\begin{array}{l}\text { Precision of } \\
\text { measurements }\end{array}$ & $\begin{array}{l}\text { Overall } \\
\text { precision }\end{array}$ & Uncertainty \\
\hline (1) $\Delta H_{c}^{\circ}\left(25^{\circ} \mathrm{C}\right) / M$, PTFE powder ... & $\mathrm{J} \mathrm{g}^{-1}$ & $-10,369.7$ & 2.7 & b 3.3 & \\
\hline (2) $\Delta H_{c}^{\circ}\left(25^{\circ} \mathrm{C}\right) / M$, PTFE film........... & $\mathrm{J} \mathrm{g}^{-1}$ & $-10,392.4$ & 5.7 & ${ }^{b} 6.0$ & \\
\hline (3) $\Delta H_{f}^{\circ}\left(25^{\circ} \mathrm{C}\right), \mathrm{BeF}_{2}$ (s, amorphous) ${ }^{\mathrm{e}}$ & $\mathrm{k} \mathrm{J} \mathrm{mol}^{-1}$ & $-1,022.22$ & 0.73 & ${ }^{\mathrm{c}} 0.96$ & $\mathrm{~d} \pm 3.2$ \\
\hline$\Delta H_{f}^{\circ}\left(25^{\circ} \mathrm{C}\right), \mathrm{BeF}_{2}(\mathrm{~s}$, amorphous $) \ldots$ & kcal mol-1 & -244.32 & 0.17 & 0.23 & \pm 0.8 \\
\hline
\end{tabular}

a Based on 95 percent confidence limits, Students' $t$ distribution.

b Includes effect of precision of $2.7 \mathrm{~J}^{\circ} \mathrm{C}^{-1}$ of energy equivalent of calorimeter.

c Includes effect of (1) and (2) as well as b.

' See table 10.

e Results of final combustions.

tion were -155.5 [12], - 310 [12], - 259 [44], - 409 [44], and $-352[44] \mathrm{kcal}^{-1}$, respectively.

Atomic weights used in the calculations were taken from the 1961 Table of Atomic Weights based on $\mathrm{C}^{12}=12$ [45]. The atomic weights of $\mathrm{Be}$ and $\mathrm{F}$ are 9.0122 and 18.9984, respectively. The unit of energy is the joule. One calorie is taken as $4.184 \mathrm{~J}$.

\subsection{Summay of Results and Estimates of Uncertainties}

Table 9 is a summary of our results and our estimates of their uncertainties. Precisions, as used here, give the 95 percent confidence limits calculated from the Student $t$ distribution. The column "precision of the measurements" was calculated from the standard deviations of the means of the measurements. The column "overall precision" includes the scatter due to the calibration experiments, item (1), and, in the case of the heat of formation of $\mathrm{BeF}_{2}(\mathrm{~s})$, item (5), also includes the scatter due to the PTFE combustion, items (2) and (3), combined as the root mean squares using the usual propagation of error formulas. The enthalpy of combustion found for PTFE powder differs by only 0.003 percent from that reported by Domalski and Armstrong [27]. The overall uncertainty is the root mean square of the systematic error and overall precision.

Estimates of the systematic errors in the heat of formation of amorphous beryllium fluoride due to recognizable uncertainties are listed in table 10 for both types of beryllium samples. Unless otherwise indicated errors are of indeterminant sign. Where a sign is given, the error is to be added to the absolute value of the heat of formation of $\mathrm{BeF}_{2}(\mathrm{~s})$. They arise respectively from (1) the initial weight of beryllium sample; (2) weight of unburned beryllium; (3) the difference in energy equivalent of the internal bomb arrangement in the calibration and fluorine experiments; (4) failure to collect all the unburned fuse; (5) the estimated change in higher fluorocarbons than $\mathrm{CF}_{4}$ in the bomb during the combustion; (6a) the weight of PTFE in a beryllium-PTFE experiment; (6b) composition and weight of the residue in PTFE combustions used to determine $\Delta E^{\circ}$ (PTFE); (7a) weight of the beryllium carbide in the products of combustion; (7b) the heat of formation of beryllium carbide; (7c) effect of assuming carbon is present in the elemental state rather than $\mathrm{Be}_{2} \mathrm{C}$ in the initial beryllium sample; (8a) weight of carbon in the residue from beryllium-PTFE combustions; (8b) effect of computing the PTFE content of the beryllium-PTFE residues on the bases of fluorine content; (8c) energy of formation of $\mathrm{CF}_{4}(\mathrm{~g})$ used in this calculation; (9) the correction for the effect of impurities in the initial beryllium sample; (10) reaction of beryllium with fluorine prior to carrying out the heat measurements; (11) corrosion of components of the combustion bomb.

The errors were calculated using $10.283 \times 10^{-3}$ and $8.963 \times 10^{-3}$ moles of $\mathrm{BeF}_{2}(\mathrm{~s})$ formed for sample type $\mathrm{BB}$ and $\mathrm{NM}$, respectively. $\Delta E^{\circ}\left(\mathrm{BeF}_{2}\right)$, item 18 of table 6 , was taken to be $1020 \mathrm{~kJ} \mathrm{~mol}^{-1}$ for both sample types.

Item (1) assumes an error of $0.02 \mathrm{mg}$ in the weight of the initial sample of beryllium. This is probably

TABLE 10. Systematic errors in $\Delta H_{\mathrm{f}}^{\circ}\left[\mathrm{BeF}_{2}(\mathrm{~s})\right]$

\begin{tabular}{|c|c|c|}
\hline Samples & BB & NM \\
\hline 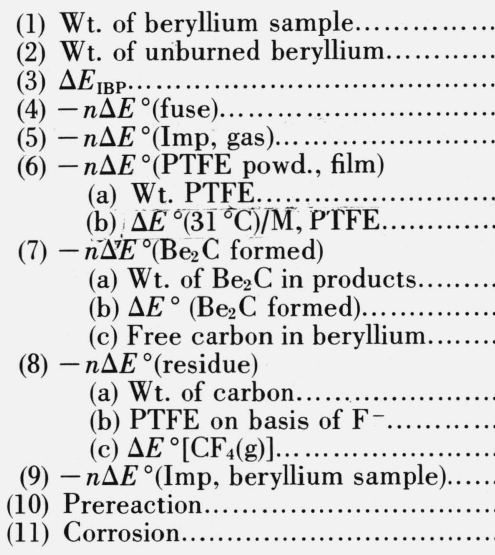 & $\begin{array}{r}0.021 \%{ }^{\mathrm{a}} \\
.011 \\
.054 \\
-.015 \\
.036 \\
.005 \\
-.023 \\
.011 \\
-.003 \\
-.051 \\
.083 \\
+.097 \\
-.023 \\
.033 \\
+.10 \\
-.10\end{array}$ & $\begin{array}{c}0.025 \%^{\mathrm{a}} \\
.15 \\
.054 \\
-.022 \\
.041 \\
\\
.005 \\
-.026 \\
\\
.045 \\
.15 \\
-.035 \\
.083 \\
\ldots \ldots \ldots \ldots . . .\end{array}$ \\
\hline Total. & $\pm 0.3 \%$ & \\
\hline
\end{tabular}

a Percentages without signs are of indeterminant sign. Those preceded by a sign are to be added to the absolute value of $\Delta H_{f}^{\circ}\left[\mathrm{BeF}_{2}(\mathrm{~s})\right]$. 
valid only when the pellet was prepared in the manner described for the final combustions.

Item (2) assumes errors of $0.01 \mathrm{mg}$ and $0.12 \mathrm{mg}$ in the weight of the unburned beryllium for samples BB and NM, respectively. These are approximately three times the a priori precision of the determinations. In the case of sample $\mathrm{BB}$, this corresponds to a 10 percent uncertainty in the average weight of unburned beryllium $(0.129 \mathrm{mg})$. The error due to the assumption that hydrogen is produced only by unburned beryllium in the combustion products appears to be within these estimates. If, for example, all impurities other than $\mathrm{BeO}(\mathrm{s}), \mathrm{Be}_{2} \mathrm{C}(\mathrm{s})$, and $\mathrm{Be}_{3} \mathrm{~N}_{2}(\mathrm{~s})$ in sample type $\mathrm{BB}$ did not react with fluorine but reacted with $\mathrm{KOH}$ to give $\mathrm{H}_{2}(\mathrm{~g})$, the resulting error would be -0.003 percent.

Item (3) is based on a 5 percent uncertainty in the heat capacity of components added to the combustion bomb for the beryllium-PTFE experiments. Item (4) assumes $0.5 \mathrm{mg}$ loss in collection of unburned fuse in the beryllium-PTFE and PTFE experiments. Item (5) is based on the uncertainties given in table 7 .

Item (6a) assumes an uncertainty in loss of PTFE film due to sealing equal to the average loss in the weight of pellets prepared for the final combustion in table 3 . Item $(6 \mathrm{~b})$ is computed on the basis that the maximum systematic error in $\Delta E^{\circ}$ (PTFE) is 0.01 percent due to assuming the residue in a PTFE combustion is PTFE. Domalski and Armstrong [27] have shown on the basis of residue analyses of PTFE combustions that this assumption is most probably true. The close similarity of our combustion arrangement to the one used in that work and the close agreement of our results $(0.007 \%)$ on the same sample of PTFE supports our estimate of an error considerably less than that caused in $\Delta E^{\circ}(\mathrm{PTFE})$, of +0.06 percent for powder and 0.14 percent for film, and in $\Delta H_{F}^{\circ}\left(\mathrm{BeF}_{2}\right)$ of -0.18 percent, if the residues from the PTFE combustions were free carbon.

Item (7a) assumes an error of $0.1 \mathrm{mg}$ and $0.03 \mathrm{mg}$ in the weight of $\mathrm{Be}_{2} \mathrm{C}$ in the products of combustion of samples $\mathrm{NM}$ and $\mathrm{BB}$, respectively (see table 8). Item $(7 \mathrm{~b})$ is based on a net uncertainty of $2 \mathrm{kcal} \mathrm{mol}^{-1}$ in the energy correction for reaction (4). Item (7c) considers the effect if carbon is present as free carbon in the initial beryllium sample.

Item (8a) assumes an uncertainty of $0.1 \mathrm{mg}$ in carbon content in the residue. Item ( $8 b)$ is the maximum correction one would obtain for the combustion experiments 6 and 7 if the fluoride and estimated average carbon contents of the residues are used. The error in sample NM is assumed to be the same. Item (8c) is the effect of altering the formation of $\mathrm{CF}_{4}(\mathrm{~g})$ from -221 to the more accurate value of $-223 \mathrm{kcal} \mathrm{mol}^{-1}$ [27]. Item (9) is based on the uncertainties in table 1 and is the net effect on the moles of $\mathrm{BeF}_{2}(\mathrm{~s})$ produced, $-n \Delta E^{\circ}\left(\mathrm{Be}_{2} \mathrm{C}\right.$ formed), and $-n \Delta E^{\circ}$ (Imp, solid).

Item (10) is based on the observed weight change in a beryllium-PTFE pellet exposed to fluorine during the preliminary combustion experiments (i.e. prior to the improvements in evacuation of the combustion bomb). The probability that poor evacuation during this experiment promoted prereaction suggests the estimate is an upper limit for the final combustion experiments. Additional evidence that substantially more prereaction was occurring during the preliminary combustions than the final combustion experiments comes from a comparison of the cooling constants of the calorimeter for the PTFE combustion experiments $^{2}$ and the beryllium-PTFE preliminary ${ }^{3}$ and final combustion ${ }^{4}$ experiments. Since one PTFE pellet as well as two beryllium-PTFE pellets ignited prematurely during the preliminary combustion experiments, it is impossible to assign the prereaction to beryllium alone during the preliminary combustions.

The basis for item (11) is the estimate of corrosion of the nickel cup in which the beryllium-PTFE pellet was burned. In a separate test, it was found that the weight change of a cup after prolonged boiling in concentrated $\mathrm{KOH}$ was negligible $(<0.02 \mathrm{mg})$. The weight increase of the cup upon exposure to fluorine was small $(\sim 0.08 \mathrm{mg})$. However, the average loss in the weight of the cups after the fluorine combustions and the reaction with concentrated $\mathrm{KOH}$ were carried out was $0.83 \mathrm{mg}$ corresponding to a loss of $1.4 \times 10^{-5}$ moles of nickel. While this is equivalent to the moles of hydrogen ascribed to unburned beryllium in the final experiments, there was no observable indication that any part of the cup during the $\mathrm{KOH}$ reaction was was giving off hydrogen. Since no pitting of the cups where the unburned beryllium had been located was observed, it seems probable the weight loss was due principally to $\mathrm{NiF}_{2}(\mathrm{~s})$ formation during the fluorine combustion and its dislodgment during the rotation of the nickel cup during the $\mathrm{KOH}$ reaction. Thus the error estimate is probably an upper limit.

The errors of indeterminant sign were combined as the square root of the sum of the squares of the individual errors to give 0.11 percent for sample BB. The total error was computed as the extremes of the sum of the errors of determinant sign and the aforementioned averages. Since the error bounds are nearly symmetrical an uncertainty of \pm 0.3 percent was taken for the systematic error and combined with the overall precision given in table 9 to yield the overall systematic error, also given in table 9.

\subsection{Discussion of Results}

The results of the preliminary beryllium-PTFE combustion experiments were assigned zero weight because of poor sample preparation and the possibility of appreciable amounts of "prereaction" of beryllium whenever the combustion bomb was poorly evacuated prior to filling with fluorine. The results were presented because the approximate agreement of those based on beryllium sample type NM, which has nearly 20 percent unreacted beryllium in the reaction products, with the final combustion experiments. We feel this lends additional confidence in the method for determining unreacted beryllium. Also, the large quantities of methane found in the gases evolved in

$22.104 \mathrm{~min}^{-1} \pm 0.003 \mathrm{~min}^{-1}$ (std. dev. of mean for 11 experiments).

$32.144 \mathrm{~min}^{-1} \pm 0.007 \mathrm{~min}^{-1}$ (std. dev. of mean for 5 experiments).

$42.102 \mathrm{~min}^{-1} \pm 0.001 \mathrm{~min}^{-1}$ (std. dev. of mean for 4 experiments). 
the combustion product reaction with $\mathrm{KOH}$ in experiments 1 and 3 , undoubtedly due to $\mathrm{Be}_{2} \mathrm{C}$, support our assumption that the small amount of methane found in the $\mathrm{KOH}$ analyses of experiments 4 through 7 also originates from $\mathrm{Be}_{2} \mathrm{C}$.

The relatively large quantity of "PTFE residue" in the beryllium-PTFEcombustion products plus the problems of determining its composition constitute a serious drawback in our experiments. As noted in section 8.1, we assumed the residue consisted solely of carbon and PTFE and computed the results using the observed carbon contents for experiments 1 and 3 and the average of the percentage carbon contents of experiments 2 and 5 for the remainder. The higher carbon contents of the residues in experiments 1 and 3 (54 and $89 \%$, respectively) as compared to the other experiments $(\sim 35 \%)$ are consistent with the presence of the much greater amount of unreacted beryllium and the formation of beryllium carbide and are unequivocal evidence that free carbon (or a fluorocarbon polymer having higher carbon content than PTFE) is present. The expectation that the carbon content of the residues of remaining experiments is relatively constant (we assume $34.6 \pm 5 \%$, item $8 \mathrm{a}$ of table 10 ) is compatible with the idea that the unreacted beryllium and amounts of $\mathrm{Be}_{2} \mathrm{C}$ are small. However, the fluoride contents of the residues of experiments 6 and 7 are in gross disagreement with the assumption of presence of only carbon and PTFE in these residues; about $0.9 \mathrm{mg}$ of other materials must be present to obtain mass balance if we assume all the fluorine is present as unburned PTFE. Even if we assume the fluoride contents are systematically low as expected [46], it is most unlikely they are low by a factor of 5 . If we had assumed that the carbon content of the residues of experiments 2 and 4-7 (all from combustion of sample type BB) was 34.6 percent, and that $1.09 \mathrm{mg}$ of residue weight is due to materials other than carbon and unburned PTFE, we would have obtained a result of $-1023.21 \mathrm{~kJ} \mathrm{~mol}^{-1}\left(244.55 \mathrm{kcal} \mathrm{mol}^{-1}\right)$ with a standard deviation of the mean of $0.15 \mathrm{~kJ} \mathrm{~mol}^{-1}(0.03$ $\mathrm{kcal}^{\mathrm{mol}}{ }^{-1}$ ). This value is 0.10 percent more negative than that adopted and is the basis for calculating item $8 \mathrm{~b}$ of table 10 . The assumption that the carbon contents of the residues of experiments 2 and 5 are low by 100 percent or more and the fluorine contents are correct appears to be most improbable. Thus, a preliminary value, obtained for the final series of combustions, before PTFE residue analyses were completed, of $-1030.5 \mathrm{~kJ} \mathrm{~mol}^{-1}\left(-246.28 \mathrm{kcal} \mathrm{mol}^{-1}\right)$, based on the assumption the residues were 88 percent carbon and 12 percent fluorine by weight as had been obtained by analysis of sample 3 , has been discarded. The higher value of the standard deviation of the mean for this result, $1.9 \mathrm{~kJ} \mathrm{~mol}^{-1}\left(0.22 \mathrm{kcal} \mathrm{mol}^{-1}\right)$, is compatible with this decision. An earlier preliminary value [11] of $-242.89 \mathrm{kcal} \mathrm{mol}^{-1}$, based on an erroneous assumption that the residues were entirely PTFE, has also been discarded.

Our value of $-244.3 \pm 0.8 \mathrm{kcal} \mathrm{mol}^{-1}$ for the heat of formation of amorphous $\mathrm{BeF}_{2}$ obtained by direct combination of the elements indicates the heat of formation of $\mathrm{BeO}(\mathrm{s})$, found by Cosgrove and Snyder [2] is too positive by one or two kilocalories. In view of the forthcoming publication by Parker [47] of a critical evaluation of thermodynamic data for beryllium compounds, ${ }^{5}$ we will not attempt a review or assessment of our value in comparison to other values in the literature here. Suffice it to say that our value is in good agreement with preliminary "best" value of the heat of formation $\mathrm{BeF}_{2}$ (glass), $-244.2 \mathrm{kcal} \mathrm{mol}^{-1}$ selected by Parker [3]. This assumes, of course, that the heat of formation of amorphous and glassy $\mathrm{BeF}_{2}(\mathrm{~s})$ are identical. Using a value of $-1.12 \mathrm{kcal}$ [48] for the enthalpy of transition of the glassy form of $\mathrm{BeF}_{2}$ (s) to the quartz form of $\mathrm{BeF}_{2}(\mathrm{~s})$, our results yield a value of $-245.44 \mathrm{k} \mathrm{mol}^{-1}$ for the heat of formation of the quartz form of $\mathrm{BeF}_{2}(\mathrm{~s})$.

\section{Gas Analysis of Solid Combustion Products}

The reaction chamber for reaction of the products of the combustion of a beryllium-PTFE pellet in fluorine with $25 \mathrm{~cm}^{3}$ of 50 weight-percent $\mathrm{KOH}$ is shown in figure 1 . The nickel cup containing the combustion products was placed in the chamber in a dry atmosphere to prevent reaction of unburned beryllium with moisture. After evacuation of the chamber to less than $10^{-3} \mathrm{~mm} \mathrm{Hg}$, the degassed $\mathrm{KOH}$ was admitted to the chamber. The reaction was carried out at room temperature for $1 \mathrm{hr}$ and then the chamber was placed in an oil bath where temperature was slowly raised and held at 80 to $100{ }^{\circ} \mathrm{C}$ for 10 to $12 \mathrm{hr}$. Kel-F grease was used on all ground glass joints. "Bumping" of the $\mathrm{KOH}$ was minimized by rotation of the nickel cup with a magnetic stirrer. The reaction chamber was found to leak consistently less than $2 \times 10^{-8}$ moles of air during this procedure.

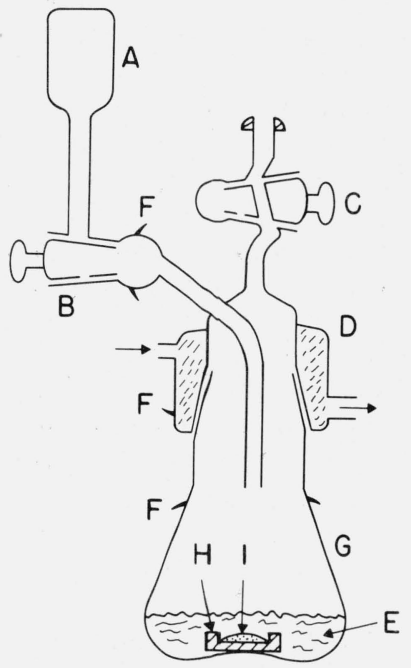

FIGURE 1. Reaction chamber for analyzing combustion residues.

A, bulb, 50- $\mathrm{cm}^{3}$, containing degassed base; B, stopcock to admit degassed base into reaction chamber; C, stopcock to gas analysis systern; D, water-cooled ground glass joint; E, base (conc. KOH); F, "wings" to secure spring clamps; G, reaction-chamber flask; H, 11/4 in diam nickel pellet cup from combustion bomb; I, solid combustion products.

${ }^{5}$ In association with the revision of NBS circular 500. (NBS Tech. Note 270 Series [12]). 


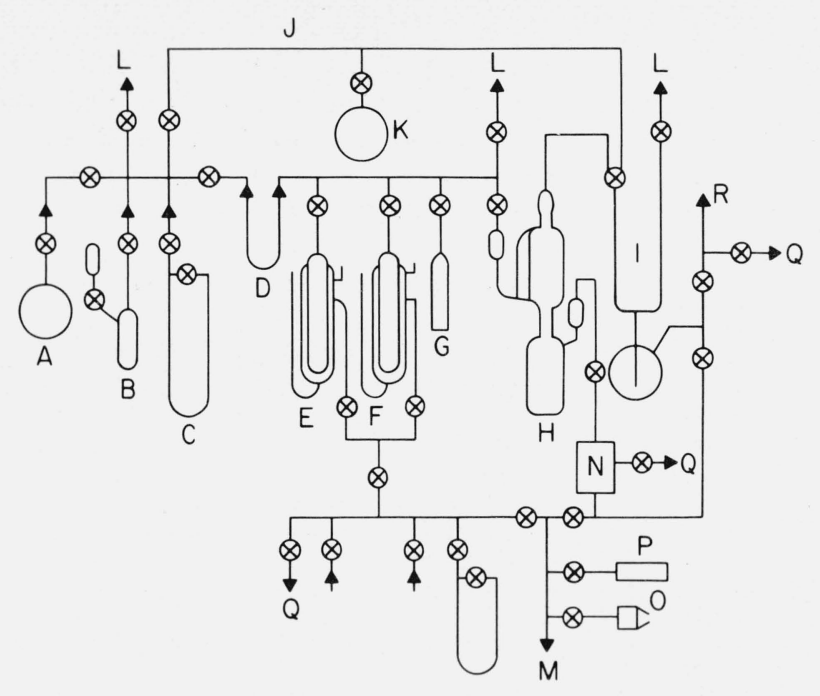

FigURE 2. Gas analysis system.

A, sample bulb; B, reaction chamber; C, mercury manometer; D, U-tube cold trap at $-78{ }^{\circ} \mathrm{C} ; \mathrm{E}$, sieve separator; $\mathrm{F}$, sieve pump; $\mathrm{G}$, thermocouple gage; H, Toepler pump I, gas burettes; J, recycle line; K, storage bulb; L, connections to vacuum pump (1); M, , connection to air pressure; $\boldsymbol{A}$ arrow head showing direction of gas flow. $\oplus$ Stopcock.

After completion of $\mathrm{KOH}$ reaction, the evolved gases were removed from the chamber by adsorption on $30 \mathrm{~g}$ of type $5 \mathrm{~A}$ molecular sieve held near $-215^{\circ} \mathrm{C}$ in a sieve separator, $\mathrm{E}$ of figure 2 , or a sieve pump, $\mathrm{F}$ of figure 2, when the amount of gas was $10^{-5}$ moles (from sample type $\mathrm{BB}$ ) or $10^{-3}$ moles (from sample type NM), respectively. An enlarged sketch of the sieve separator (the sieve pump is identical) is shown in figure 3. Gas collected using the sieve separator was released by warming the separator to room temperature and measuring the total moles of gas in the gas burete, I of figure 2. Part of the gas was then analyzed mass spectrometrically and the remainder by the sieve separator. Aliquots of the gas collected by use of the sieve pump were released from the sieve pump by progressive warming, separated by the sieve separator, and measured with the gas burette. A check of possible contamination of the gas fractions was carried out by mass spectrometric methods. The sieve separation procedure consisted of warming the separator to $-190{ }^{\circ} \mathrm{C}$ or lower to release hydrogen, -180 to $-170{ }^{\circ} \mathrm{C}$ to release $\mathrm{N}_{2}$ and $\mathrm{O}_{2}$ from air, if present, and $-130{ }^{\circ} \mathrm{C}$ to room temperature to release methane and small amounts of other gases. The purity of the fractions was maximized by slowly warming the separator and maintaining the "separation temperature" for $1 \mathrm{hr}$.

Measurements of burete temperature, volume, and pressure had overall uncertainties of $0.1{ }^{\circ} \mathrm{C}, 0.03 \mathrm{~cm}^{3}$, and $0.02 \mathrm{~mm}$ of $\mathrm{Hg}$, respectively. Experience showed that the precisions for a single measurement of the quantity of gas in the burete were $1,0.15$, and 0.10 percent for $2 \times 10^{-5}, 2 \times 10^{-4}$, and $1.1 \times 10^{-3}$ moles of gas, respectively.

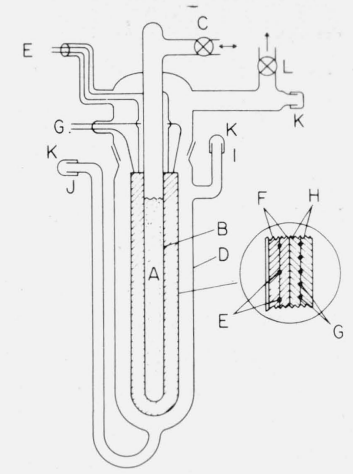

FiguRE 3. Sieve separator

A, type $5 \mathrm{~A}$ molecular sieve; B, sieve well; C, stopcock to gas analysis system; D, jacket; $\mathrm{E}$, thermocouples; $\mathrm{F}$, aluminum foil; $\mathrm{G}$, heater wire; $\mathrm{H}$, asbestos tape; I, liquid nitrogen E, thermocouples; $F$, aluminum foil; $G$, heater wire; $H$, asbestos tape; 1 , liquid nitrogen pumping on liquid nitrogen. The inset shows an enlarged detail of the heater element, $\mathrm{M}$

Table 11 is a comparison of the molecular-sieveseparation and mass-spectrometer analysis of about $2 \times 10^{-5}$ moles of gas liberated by the reaction of $\mathrm{KOH}$ with the solid combustion products. Experiment numbers correspond to those in table 7 of the combustion experiments. Mass spectrometer values of $\mathrm{N}_{2}, \mathrm{O}_{2}, \mathrm{Ar}$, and $\mathrm{CH}_{4}$ were added to give the value of $\mathrm{CH}_{4}$ since the "methane fraction" of the sieve analysis would be expected to contain all these components. The largest uncertainties of the mass spectrometer analyses (esti-

TABLE 11. Comparison of analysis by mass spectrometer and by molecular sieve absorption

[In percent]

\begin{tabular}{|c|c|c|c|}
\hline \hline Ingredient & $\begin{array}{c}\text { Mass spec- } \\
\text { trometer }\end{array}$ & Sieve & Difference \\
\hline
\end{tabular}

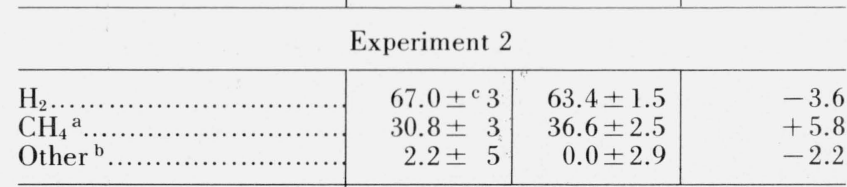

Experiment 5

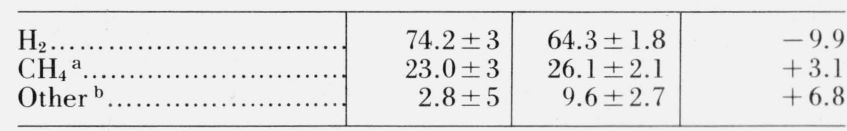

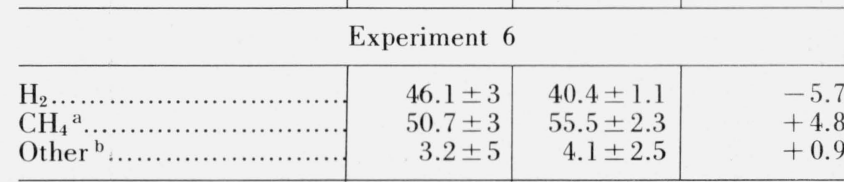

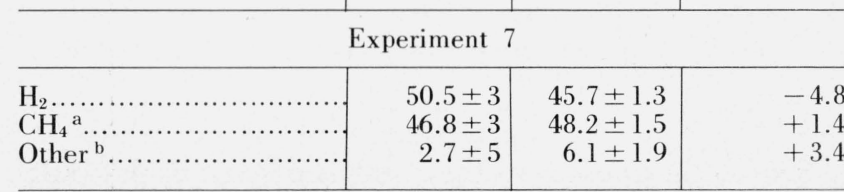

a Includes 5.0 to 7.6 percent $\mathrm{N}_{2}, \mathrm{O}_{2}$ and $\mathrm{Ar}$ observed in the mass spectrometer.

${ }^{b}$ In the mass spectrometer this was observed as $\mathrm{H}_{2} \mathrm{O}$, acetone, propene, propane, and other hydrocarbons.

${ }^{\mathrm{C}}$ Uncertainty estimated by mass spectrometer analyst. 
mated by the analyst) are those for hydrogen and methane. The uncertainties of the sieve analyses are the estimated 95 percent confidence limits assuming the standard deviation of a single measurement of the quantity of gas to be 1 percent. Although it is apparent there may be some discrepancies between the two analyses, the agreement is well within the requirements for our problem (see sec. 9.1). Neither the origin of the small quantities of hydrocarbons, present in all the combustion product analyses, or the $\mathrm{N}_{2}$ or $\mathrm{O}_{2}$ is known with certainty.

The fraction listed as "other" in table 11 was the portion observed in the mass spectrometer as $\mathrm{H}_{2} \mathrm{O}$ vapor and organic substances more complex than methane. For the molecular sieve analysis it was all material not recovered in either the $\mathrm{H}_{2}$ or $\mathrm{CH}_{4}$ fraction.

Table 8 contains a summary of the combustion product analyses based on the molecular sieve gas separations. Methane, for experiments 2, 5, 6, and 7 was calculated from the moles of gas in the "methane fraction" given by the sieve analyses adjusted for small amounts of other gases in this fraction given by the mass spectrometer analyses. Since no mass spectrometer analysis was made for experiment 4 , the percent of methane in the sieve analysis "methane fraction" was estimated from the results of the above experiments. Methane and hydrogen for experiments 1 and 3 where the total moles of gas was large (i.e., $2 \times 10^{-3}$ ), were calculated using the results of the sieve analysis and corrections for the relatively small amounts of impurities (air, methane in the hydrogen fraction of the sieve analysis from 0.2 to $0.4 \%$ ) given by the mass spectrometer analyses.

Table 12 lists two of the test runs made to check the accuracy and precision of the sieve separator.

TABLE 12. Tests of molecular sieve separator

\begin{tabular}{|c|c|c|}
\hline Ingredient & $\begin{array}{l}\text { Initial } \\
\text { composition } \\
\text { moles } \times 10^{4} \text { a }\end{array}$ & $\begin{array}{l}\text { Analyzed } \\
\text { composition } \\
\text { moles } \times 10^{4}\end{array}$ \\
\hline \multicolumn{3}{|c|}{ a Sample 1, separation temperature, $-144{ }^{\circ} \mathrm{C}$} \\
\hline 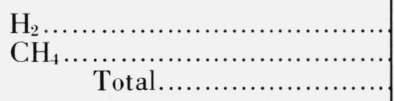 & $\begin{array}{ll}3.367 \pm \mathrm{b} & 0.004 \\
2.031 & .003 \\
5.398 & .005\end{array}$ & $\begin{array}{lr}3.354 \pm{ }^{\mathrm{b}} & 0.004 \\
2.049 & .003 \\
5.403 & .005\end{array}$ \\
\hline \multicolumn{3}{|c|}{${ }^{\mathrm{b}}$ Sample 2 , separation temperature, $-130^{\circ} \mathrm{C}$} \\
\hline 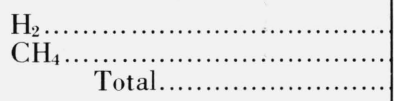 & $\begin{aligned} & 1.474 \pm 0.002 \\
&> 2.0 \\
& \ldots \ldots \ldots \ldots \ldots \ldots \ldots \ldots\end{aligned}$ & $\begin{aligned} & 1.478 \pm 0.002 \\
&> 2.0 \\
& \ldots \ldots \ldots \ldots \ldots \ldots \ldots\end{aligned}$ \\
\hline
\end{tabular}

a The initial composition was determined by prepurification of the gas samples with the sieve separator and measurement of the quantity of each by a gas burette. Purity was checked by mass spectra.
che

checked by mass spectra.
bUncertainties are estimated 95 percent confidence limits, Students' $t$ distribution (based on actual observations).

The authors express their indebtedness to the NBS Analysis and Purification Section of the Analytical Chemistry Division for the numerous analyses that form an integral part of this work. In particular, we wish to thank William D. Dorko for the mass spectra, Rolf A. Paulsen for the analysis of the carbon-PTFE residues, and Mrs. E. June Maienthal for the analysis of $\mathrm{BeF}_{2}(\mathrm{~s})$. The authors express their thanks to Eugene S. Domalski for the advice and instruction given to one of us (K.L.C.) in fluorine bomb calorimetry.

\section{References}

[1] Kolesov, V. P., Popov, M. M., and Skuratov, S. M., Zh. Neorg. Khim 4, 1233-6 (1959) (J. Inorg. Chem. (USSR) 4, 557-8 (1959)).

[2] Cosgrove, L. A., Snyder, P. E., J. Am. Chem. Soc. 75, 3102-3 (1953).

[3] Parker, V. B., Informal communication, January 1967.

[4] Roth, W. A., Boerger, E., and Siemonsen, H., Z. anorg. u. allgem. Chem. 239, 321-326 (1938).

[5] Neuman, B., Kroeger, C., and Kunz, H., Z. anorg. u. allgem. Chem. 218, 379-401 (1934).

[6] Moose, J. E., and Parr, S. W., J. Am. Chem. Soc. 46, 2656-61 (1924).

[7] Mielenz, W., and von Wartenberg, H., Z. anorg. u. allgem. Chem. 116, 267-8 (1921), W. Mielenz, Dissertation, Berlin, 1914.

[8] Simmons, J., Atlantic Research Corp., private communication, 1962.

[9] Gross, P., Fulmer Research Institute, private communication, November 1960.

[10] Domalski, E. S., and Armstrong, G. T., J. Res. NBS 69A (Phys. and Chem.), No. 2, 137-147 (1965).

[11] Armstrong, G. T., Coyle, C. F., American Chemical Society, Western Regional Meeting, Los Angeles, California, November 18-20, 1965 (Gmelin Reference No. AED-Conf. 65-358-1, Nuclear Science Abstracts 20 , No. 42369).

[12] Wagman, D. D., Evans, W. H., Parker, V. B., Halow, I., Bailey, S. M., Schumm, R. H., Selected values of Chemical Thermodynamic Properties Tables for the first Thirty-four Elements in the Standard Order of Arrangement, NBS Technical Note 270-3, January 1968, Supt. of Document, U.S. Govt. Printing Office, Washington, D.C. 20402.

[13] Wise, S. S., and Margrave, J. L., J. Phys. Chem. 67, 815-821, 1963.

[14] Armstrong, G. T., and Krieger, L. A., Heats of Formation of Inorganic Fluorine Compounds-A Survey, Chapter 2. Progress in Internatl. Research on Thermodynamic and Transport Prop., J. F. Masi and D. H. Tsai, Eds. (Academic Press, New York, 1962).

[15] Settle, J. L., Feder, H. M., and Hubbard, W. N., J. Phys. Chem. 65, 1337-40 (1961).

[16] Armstrong, G. T., and Jessup, R. S., J. Res. NBS 64A (Phys. and Chem.), No. 1, 49-59 (1960).

[17] Dickinson, H. C., Bull. BS 11, 189-257 (1914).

[18] Prosen, E. J., Johnson, W. H., and Pergiel, F. Y., J. Res. NBS 62, 43-7 (1959) RP2927.

[19] Coops, J., Jessup, R. S., and Van Nes, K., Chapter 3, Experimental Thermochemistry, F. D. Rossini, Editor (Interscience Publishers, Inc., New York, 1956).

[20] Jessup, R. S., Precise Measurement of Heat of combustion in a bomb calorimeter, NBS Monograph No. 7, February 26, 1960.

[21] Darwin, G. E., and Buddery, J. H., Beryllium (Academic Press, Inc., New York 1960).

[22] White, D. W., Jr., and Burke, J. E., The Metal Beryllium (American Society for Metals, Cleveland, 1955).

[23] Breslin, A. J., and Harris, W. B., Health Protection in Beryllium Facilities; Summary of Ten Years Experience (Health and Safety Laboratory, U.S.A.E.C., New York Operations Office, May 1, 1958).

[24] Tepper, L. B., Hardy, H. L., and Chamberlin, R. I., Toxicity of Beryllium Compounds (Elsevier Publishing Co., Amsterdam, New York, 1960).

[25] Mears, T. W., Johnson, W. H., and Gilliland, W. A., NBS private communications, 1962.

[26] Domalski, E. S., and Armstrong, G. T., J. Res. NBS 71 A (Phys. and Chem.), No. 2, 105-118 (1967). 
[27] Domalski, E. S., and Armstrong, G. T., J. Res. NBS 71A (Phys. and Chem.) No. 3, 195-202 (1967).

[28] Domalski, E. S., and Armstrong, G. T., J. Res. NBS $71 \mathbf{A}$ (Phys. and Chem.) No. 4, 307-315 (1967).

[29] Domalski, E. S., and Armstrong, G. T., J. Res. NBS 72A (Phys. and Chem.) No. 2, 133-139 (1968).

[30] Warren, B. E., and Hill, C. F., Z. Krist. 89, 31 (1935).

[31] Hubbard, W. N., Scott, D. W., and Waddington, G., Chapter 5, Experimental Thermochemistry, F. D. Rossini, Editor (Interscience Publishers, Inc., New York, 1956).

[32] Hubbard, W. N., Chapter 5, Vol. II, Experimental Thermochemistry, H. A. Skinner, Editor (Interscience Publishers, Inc., New York, 1962).

[33] Handbook of Chemistry and Physics, 44th edition (Chemical Rubber Publishing Company, Cleveland, Ohio, 1962).

[34] Meyers, O. E., and Brady, A. P., J. Phys. Chem. 64, 591 (1960).

[35] White, D., Hu, J. H., and Johnston, H. L., J. Phys. Chem. 21, 1149 (1953).

[36] Douslin, D. R., Paper 11, Progress in International Research on Thermodynamic and Transport Properties, J. F. Masi and D. H. Tsai, Editors (Academic Press, New York, 1962).

[37] Evans, W. H., Hilsenrath, J., and Woolley, H. W., private communication, July 1960.
[38] Dow Chemical Company, JANAF Thermochemical Tables. PB168370 (Clearinghouse for Federal Scientific and Technical Information, Springfield, Virginia, 1965).

[39] Furukawa, G. T., Reilly, M. L., Henning, J. M., Douglas, T. B., Victor, A. C., and Beaudoin, A. R., Informal communication, July 1959

[40] Good, W. D., Scott, D. W., and Waddington, G., J. Phys. Chem. 60, 1080 (1956).

[41] Furukawa, G. T., and Reilly, M. L., informal communication, January 1964.

[42] Stephenson, C. C., Hopkinson, H. P., Jr., and Wulff, C. A., J. Phys. Chem. 68, 1427-29 (1964).

[43] Rossini, F. D., Wagman, D. D., Evans, W. H., Levine, S., and Jaffe, I., NBS Circular 500, February 1952.

[44] Patrick, C. R., The Thermochemistry of Organic Fluorine Compounds, Vol. 2, M. Stacey, J. C. Tatlow, A. G. Sharpe, Editors, (Butterworths, Washington, i961).

[45] Cameron, A. E., and Wichers, E., J. Am. Chem. Soc. 84, 4175 (1962).

[46]. Paulson, R. A., NBS, private communication.

[47] Parker, V. B., NBS, private communication (to be published in J. Research NBS).

[48] Taylor, A. R., Gardner, T. E., U.S. Bureau of Mines Rept. Invest. 6664 (1965).

(Paper 73A3-552) 